\title{
Chronic psychological stress and its impact on the development of aggressive breast cancer
}

\author{
Estresse psicológico crônico e seu impacto no desenvolvimento \\ de neoplasia mamária agressiva
}

\author{
Thayse Fachin Cormanique ${ }^{1}$, Lirane Elize Defante Ferreto de Almeida ${ }^{1}$, Cynthia Alba Rech ${ }^{2}$, \\ Daniel Rech ${ }^{2}$, Ana Cristina da Silva do Amaral Herrera ${ }^{3}$, Carolina Panis ${ }^{1}$
}

\begin{abstract}
Objective: To investigate the clinicopathological findings of women diagnosed with breast cancer and study the impact of chronic psychological stress on the pathological characteristics of these tumors. Methods: We investigated a cohort composed of women diagnosed with breast cancer and divided into two groups. One group was categorized as presenting with chronic psychological stress (by using the Self-Reporting Questionnaire - SRO-20). Another group of women with breast cancer, but with no previous history of chronic psychological stress, comprised the Control Group. Clinical and pathological data were assessed. Results: Women presenting with a history of chronic distress were significantly overweight when compared to the Control Group. Furthermore, it was observed that these stressed women also had a significant percentage of aggressive breast cancer subtype, the HER2 amplified tumor, which could be putatively associated with the loss of immunosurveillance. Conclusion: Our findings suggested an interaction among chronic psychological stress, overweight, and the development of more aggressive breast tumors.
\end{abstract}

Keywords: Stress, psychological; Breast neoplasms; Overweight; Obesity; Monitoring, immunologic

\section{RESUMO}

Objetivo: Investigar os achados clínico-patológicos de mulheres diagnosticadas com câncer de mama e estudar o impacto do estresse psicológico crônico nas características patológicas desses tumores. Métodos: Investigamos uma coorte composta por mulheres diagnosticadas com câncer de mama divididas em dois grupos. 0 primeiro foi classificado pela apresentação de estresse psicológico crônico (por meio do Self-Reporting Questionnaire - SRQ-20). Outro grupo de mulheres com câncer de mama, mas sem história prévia de estresse psicológico crônico, foi denominado Grupo Controle. Os dados clínicos e patológicos foram avaliados. Resultados: As mulheres com histórico de estresse crônico apresentaram-se significativamente acima do peso quando comparadas com o Grupo Controle. Além disso, verificou-se que estas mulheres estressadas apresentaram um porcentual significativo de um subtipo de câncer de mama agressivo, o HER2, o que poderia estar associado à possível perda da imunovigilância. Conclusão: Nossos resultados sugeriram uma ligação entre o estresse psicológico crônico, o excesso de peso e 0 desenvolvimento de tumores de mama com maior agressividade.

Descritores: Estresse psicológico; Neoplasias da mama; Sobrepeso; Obesidade; Monitorização imunológica

\section{INTRODUCTION}

Breast cancer is a multifactorial disease, consisting of a public health problem worldwide. Some factors that interact among themselves contribute to the high incidence of breast cancer, including family history, presence of high-susceptibility genes, excessive body weight, and chronic stress. ${ }^{(1-3)}$

In this context, chronic psychological stress is a common finding reported by cancer patients. Stressful life events are considered important components that can affect the emotional state of the individuals, and their association with loss of social support is even related to significantly shortened survival in breast cancer patients. ${ }^{(4)}$ There is a significant positive association between early life distress and breast cancer development. ${ }^{(5)}$ Furthermore,

\footnotetext{
' Universidade Estadual do Oeste do Paraná, Francisco Beltrão, PR, Brazil.

${ }^{2}$ Hospital do Câncer de Francisco Beltrão, Francisco Beltrão, PR, Brazil.

${ }^{3}$ Pontifícia Universidade Católica do Paraná, Londrina, PR, Brazil.

Corresponding author: Carolina Panis - Rua Maringá, 1.200 - Vila Nova - Zip code: 85605-010 - Francisco Beltrão, PR, Brazil - Phone: (55 46) 3055-3026 - E-mail: carolpanis@hotmail.com

Received on: Mar 1, 2015 - Accepted on: Aug 10, 2015

Conflict of interest: none.
}

DOI: 10.1590/S1679-45082015A03344 
a systematic analysis of some studies published in the last 30 years, investigating the causal attributions in breast cancer patients, demonstrated that breast cancer patient survivors consistently associate their disease with emotional distress, among another factors. ${ }^{(6)}$

Concerning the biological impact of chronic distress, the sustained psychological stress alone can lead to weight gain through several biological mechanisms, ${ }^{(2)}$ which may potentially result in loss of immunosurveillance. ${ }^{(7)}$ Competent immune responses are the major defense against cancer; therefore, their impairment is strongly associated with the development of several types of cancer, including breast tumors that confer poor prognosis. $^{(8)}$

Although the relation between cancer development and chronic stress has been described, little is known concerning the impact of chronic psychological stress in the phenotype of breast tumors. To clarify this question, we investigated if women presenting with chronic emotional distress could exhibit more aggressive phenotypes of breast cancer.

\section{OBJECTIVE}

To investigate clinicopathological findings from women diagnosed with breast cancer, and study the impact of chronic psychological stress in the pathological characteristics of tumors.

\section{METHODS}

\section{Study design}

This study included women living in the State of Paraná, diagnosed with infiltrative carcinoma of the breast, in the period from August 2013 to July 2014. They had been previously scheduled to undergo chemotherapy on a set day of the week, the same period. The selection of patients was conducted at the Centro de Oncologia de Francisco Beltrão (Ceonc), in the city of Francisco Beltrão (PR), Brazil. The inclusion criteria adopted were women with infiltrative ductal carcinoma of breast, uni- or bilateral, diagnosed between August 2013 and July 2014, eligible according to the Self-Reporting Questionnaire (SRQ-20) as stress or non-stress cohorts. To determine the sample size, we applied the following statistical calculation, in which: $\mathrm{N} 0=$ size number, $\mathrm{Z}=$ confidence interval, $\mathrm{P}=$ probability, $\mathrm{D}=$ error margin, $\mathrm{n}=$ sample size, and $\mathrm{N}=$ population size:

$$
n_{0}=\frac{Z^{2} \cdot p(1-p)}{D^{2}} \text { and } \quad n=\frac{n_{0}}{1+\frac{n_{0}}{N}}
$$

Considering that (1) our population was approximately 100 thousand inhabitants; (2) a p value of 0.05 ; (3) according to the Instituto Nacional de Câncer estimate, the incidence of breast cancer in this region was roughly 61 cases per 100 thousand women; (4) there were about 30 thousand women in the age range of risk for breast cancer in this area, thus, we have that the minimal sample size of about 18 patients was needed. Taking into account the period of the study and the fact that we worked with patients previously scheduled on a fixed day of the week to undergo chemotherapy, we decided to include 17 patients in each group. In this context, this study enrolled 34 women diagnosed with infiltrative ductal carcinoma of the breast. This study was previously approved by the Institutional Review Board, and all participants signed the Informed Consent Form. The research project was approved by the National Council of Scientific Research Ethics Committee, under number 497.050 and CAAE: 22027213.7.0000.0107. Clinical records were assessed and the data collected included age at diagnosis, weight, height, comorbidities, TNM classification, and chemotherapy regimen.

For determining the chronic psychological stress status of patients, we conducted an initial interview to verify the social support of the patient (family income, type of residence, level of education, life style, and social relationships), since we did not know if the patients were from different social conditions. Because all patients reported similar socioeconomic data, we continued the study by applying the SRQ-20 for psychiatric disorder screening. ${ }^{(9)}$ This interview was applied to patients that were in the hospital for routine chemotherapy treatment during the period of the study.

The women enrolled in this study were categorized into two groups: Control Group $(\mathrm{n}=17)$, with women diagnosed with breast cancer with no previous history of chronic psychological stress; Stress Group $(n=17)$, with women diagnosed with breast cancer with a past history of chronic psychological stress.

\section{Molecular subtyping of breast tumors by immunohis- tochemistry}

Formalin-fixed, paraffin-embedded samples from tumor biopsies were immunostained with primary antibodies for estrogen receptor (ER; anti-human estrogen receptor alpha, clone 1D5 at 1:600; Dako, Dinamarca), progesterone receptor (PR; anti-human progesterone, clone PGR 636 at 1:500; Dako, Dinamarca), and human epidermal growth receptor 2 (HER-2, anti-human HER2-pY-1248, clone PN2A at 1:500; Dako, Dinamarca), in association with a commercial immunohistochemistry kit. Samples were 
considered positive for ER/PR when at least $10 \%$ of the tumor cell nuclei were stained. HER2 was considered overexpressed when strong membrane staining $(3+)$ was detected or when amplification of HER2 in samples with moderate $(2+)$ membrane staining was observed in Fluorescent in Situ Hybridization (FISH) analysis. Samples were scored and categorized. They were considered HER2-positive when the HER2 IHC score was $3+$, and HER-negative when the score was $1+$ or zero. Samples with a $2+$ score were analyzed by FISH to detect HER2 amplification (HER2 FISH pharmDx ${ }^{\mathrm{TM}}$; Dako, Dinamarca). Samples with a $2+$ IHC score and an amplified result in FISH were considered HER2positive, while samples with a $2+$ IHC score and a nonamplified in FISH were considered HER2-negative. ${ }^{(10)}$

\section{Data analysis}

For clinicopathological parameters, data were expressed as the mean \pm standard error of the mean. All data were compared by using the non-parametric Mann-Whitney test. A p value $<0.05$ was considered significant. All statistical analyses were performed using the GraphPad Prism software version 5.0 (GraphPad Prism Software, San Diego, CA, USA).

\section{RESULTS}

The mean age at diagnosis was 60.2 years. We found that $40 \%$ of patients were diagnosed as having breast cancer by routine mammograms, and $53 \%$ reported perception of nodules in the breasts by self-examination. The remaining $7 \%$ had no palpable nodules, but felt pain in breast and went to a doctor for this reason. Regarding the verification of chronic psychological stress (Table 1), it was observed that $79 \%$ reported a history of chronic psychological stress. The most common traumas related were death of family members, abandonment by a partner, employment loss, sexual abuse, and major depression. Moreover, $73 \%$ of patients associated the occurrence of chronic psychological stress with breast cancer development. A total of $47 \%$ were classified as potential carriers of psychic disorders by the SRQ20. The patients who reported a positive history of psychological stress were categorized to form the Stress Group.

Aiming to understand the clinicopathological impact of chronic psychological stress on breast cancer and clinical features, we compared the data from the Stress Group with a control cohort, composed of women diagnosed with breast cancer with no past history of
Table 1. Main parameters employed for chronic psychological stress characterization

\begin{tabular}{lc}
\hline Parameter & Mean percentage \\
\hline Family relationships & 85 \\
Good & \\
Types of psychological distress reported & 36 \\
Death of relatives & 9 \\
Loss of employment & 18 \\
Abandonment by partner & 9 \\
Sexual abuse & 9 \\
Depression & 19 \\
Other emotional distress & \\
Received support during the treatment & 93 \\
Yes & \\
Presented difficulty for abandoning work & 57 \\
Yes & \\
Believes that chronic stress is associated as a cause of \\
the disease \\
Yes \\
Risk for developing mental disorders \\
Yes
\end{tabular}

chronic emotional stress. In this context, figure 1 shows that the Control Group comprised mainly women with breast cancer presenting with a normal body mass index (BMI) (90\%). On the other hand, patients from the Stress Group exhibited a significant predominance of overweight women $(54 \% ; \mathrm{p}=0.0041)$. The molecular subtyping of breast tumors (Figure 2) indicated the predominance of HER2 positive tumors in the Stress Group when compared to controls $(31 \pm 1.41 \%$ versus $12 \pm 0.05 \% ; \mathrm{p}=0.0136)$.

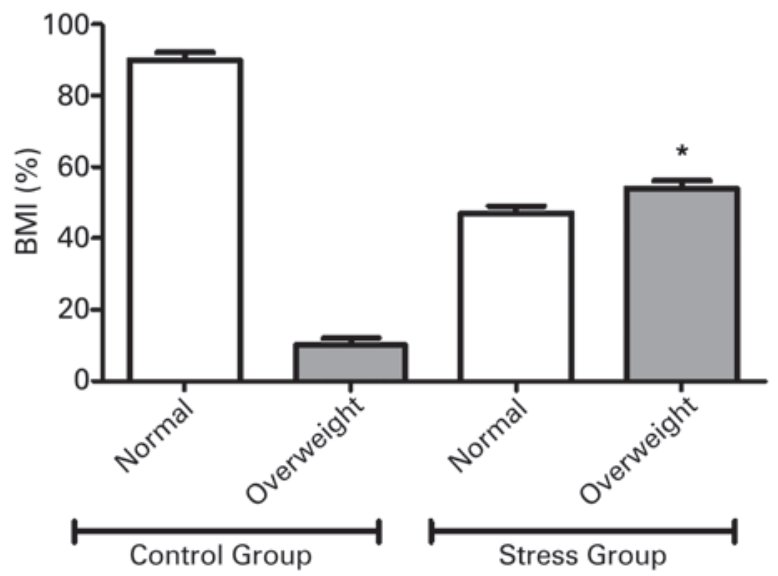

*Statistically significant difference $(p<0.05)$, Mann-Whitney test; BMI: body mass index

Figure 1. Analysis of body mass indexes. We used the International Classification of Body Mass Index to categorize the patients into normal weight (BMI up to $25 \mathrm{~kg} / \mathrm{m}^{2}$ ) or overweight (BMI above $25 \mathrm{~kg} / \mathrm{m}^{2}$ ) 


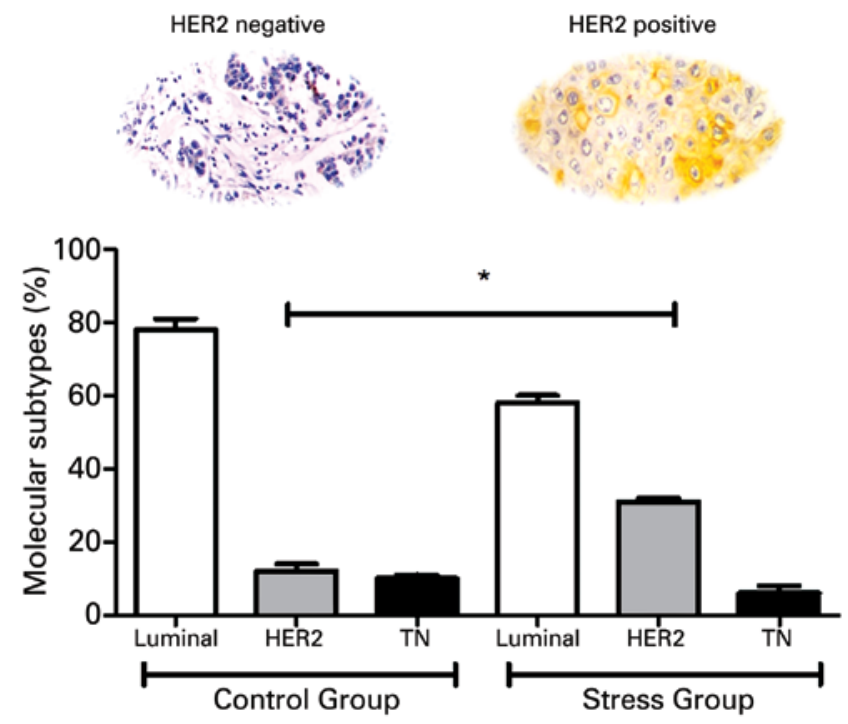

HER2: human epithelial growth factor receptor 2; TN: triple negative tumors. *Significant statistical difference $(p<0.05)$, Mann-Whitney's test.

Figure 2. Molecular subtyping of tumors. The images represent the IHC labeling for HER2

\section{DISCUSSION}

For the last years, breast cancer has been the leading malignant neoplasm in women worldwide. This fact deserves attention, since the list of risk factors related with this disease is growing. Our aim was to investigate women diagnosed with breast cancer who reported a past history of chronic psychological stress and its impact on clinicopathological aspects of breast cancer. To reach this goal we initially applied the SRQ-20 as a psychiatric screening tool to compose the stress cohort.

The SRQ-20 is an instrument developed by the World Health Organization (WHO) to screen psychiatric disorders in patients. It detects symptoms, such as anxiety, depression, and psychosomatic complaints with adequate accuracy. ${ }^{(11)}$ The SRQ-20 was previously applied and validated in the Brazilian population, ${ }^{(9)}$ including breast cancer patients. ${ }^{(12)}$ Our data demonstrated that about $47 \%$ of patients seen during the period of the SRQ-20 application were categorized as presenting with psychiatric distress and included in the Stress Group.

We further selected another cohort of patients who had a similar clinical history (age at diagnosis, family history, general health status, and family income), but with no prior report of chronic psychological stress to compose the Control Group. We employed this approach aiming to compare the impact of chronic emotional distress on clinical and pathological characteristics of breast tumors, in both groups. Our data indicated that a significant portion of the women enrolled in the Stress Group were overweight when compared to those of the Control Group. Both psychological stress and overweight are important risk factors for breast cancer development. ${ }^{(1,2)}$ Under chronic stress conditions, there is a systemic rise in cortisol levels, which increases appetite and favors the storage of lipids in adipose tissue.(2) This set of biological events that contributes to weight gain is made up of relevant risk factors for breast cancer in the modern society, ${ }^{(8)}$ and may partly help to understand the results found in the present study. Overweight increases the risk for breast cancer recurrence after the primary tumor excision, and significantly reduces the overall survival of patients ${ }^{(13)}$ by affecting the spreading of breast cancer cells. ${ }^{(14)}$ This evidence helps to understand the important percentage of women with locally advanced disease upon diagnosis in the Stress Group.

It is well-established that chronic inflammation induced by the excessive availability of lipids found during overweight and obesity conditions can promote cancer spreading and aggressiveness, a process mediated by tumor-driven cytokines. ${ }^{(1)}$ Together, chronic psychological stress and overweight can impair immunosurveillance as shown in breast cancer patients by Varker et al. ${ }^{(7)}$ Altogether, these factors are putative stimuli for developing breast tumors with aggressive characteristics.

Based on this hypothesis, we investigated the phenotypic profile of breast tumors in both groups. Our data revealed that women with a history of psychological stress displayed a significant percentage of tumors overexpressing HER2. HER2-amplified breast tumors promote aggressive disease, with poor prognosis ${ }^{(14-16)}$ due to its rapid proliferation and spreading. ${ }^{(17,18)}$ These tumors are reported in overweight/obese women, which exhibit enhanced disease spreading in relation to non-obese patients. ${ }^{(8)}$ In this case, the excessive bioavailability of lipids seems to favor the epithelial transformation of cells into HER2-amplified neoplastic cells. ${ }^{\left({ }^{(9)}\right)}$ Menendez ${ }^{(20)}$ demonstrated that HER2 cancers take advantage of lipids as their energy source, which is strongly favored in environments rich in fat, such as the breast tissue of overweight or obese women. We further observed that most patients presented with the HER2-amplified tumor mass located in the left breast. The left mammary gland frequently presents more breast tissue than the right, which may benefit fat accumulation and cancer development. ${ }^{(21)}$

These data support the hypothesis that the women enrolled in the present study have a complex chain formed by historical factors of psychological stress, overweight, and development of phenotypically aggressive breast tumors. Our preliminary findings suggest a "vicious circle" involving chronic psychological stress, overweight, and breast cancer aggressiveness. 
The main limitations of our study included the small sample size and the need for a long-term follow-up of patients to examine the recurrence of the disease and responsiveness to chemotherapy.

\section{CONCLUSION}

Our data suggest that chronic psychological stress may represent a considerable risk factor for weight gain and development of aggressive tumors in women diagnosed with breast cancer, such as human epidermal growth factor receptor 2-amplified breast tumors.

\section{ACKNOWLEDGEMENTS}

The authors are grateful to the Conselho Nacional de Desenvolvimento Científico e Tecnológico (CNPq) for grant support, and to the Centro de Oncologia de Francisco Beltrão (Ceonc) staff for providing excellent technical support.

\section{REFERENCES}

1. Huang CJ, Zourdos MC, Jo E, Ormsbee MJ. Influence of physical activity and nutrition on obesity-related immune function. ScientificWorldJournal. 2013 7;2013:752071. Review.

2. Sominski L, Spencer SJ. Eating behavior and stress: a pathway to obesity. Front Psychol. 2014;5:434. Review.

3. Paiva CE, Ribeiro BS, Godinho AA, Meirelles RS, Silva EV, Marques GD, et al. Fatores de risco para câncer de mama em Juiz de Fora (MG): um estudo caso-controle. Rev Bras Cancerol. 2002;48(2):231-7.

4. Kornblith $A B$, Herndon JE 2nd, Zuckerman E, Viscoli CM, Horwitz Rl, Cooper MR, Harris L, Tkaczuk KH, Perry MC, Budman D, Norton LC, Holland J; Cancer and Leukemia Group B. Social support as a buffer to the psychological impact of stressful life events in women with breast cancer. Cancer. 2001;91 (2):443-54.

5. Kennedy B, Valdimarsdóttir U, Sundström K, Sparén, P, Lambe M, Fall K, et al. Loss of a parent and the risk of cancer in early life: a nationwide cohort study. Cancer Causes Control. 2014;25(4):499-506.

6. Dumalaon-Canaria JA, Hutchinson AD, Prichard I, Wilson C. What causes breast cancer? A systematic review of causal attributions among breast cancer survivors and how these compare to expert-endorsed risk factors. Cancer Causes Control. 2014;25(7):771-85. Review.
7. Varker KA, Terrell CE, Welt M, Suleiman S, Thornton L, Andersen BL, et al. Impaired natural killer cell lysis in breast cancer patients with high levels of psychological stress is associated with altered expression of killer immunoglobulin-like receptors. J Surg Res. 2007;139(1):36-44.

8. Mazzarella L, Disalvatore D, Bagnardi V, Rotmensz N, Galbiati D, Caputo S, et al. Obesity increases the incidence of distant metastases in oestrogen receptor-negative human epidermal growth factor receptor 2-positive breast cancer patients. Eur J Cancer. 2013;49(17):3588-97.

9. Mari JJ, Williams P. A validity study of a psychiatric screening questionnaire (SRO-20) in primary care in the city of São Paulo. Br J Psychiatry. 1986;148:23-6.

10. Victorino VJ, Campos FC, Herrera AC, Colado Simão AN, Cecchini AL, Panis C, et al. Overexpression of HER-2/neu protein attenuates the oxidative systemic profile in women diagnosed with breast cancer. Tumour Biol. 2014;35(4): 3025-34.

11. Sartorius N, Janca A. Psychiatric assessment instruments developed by the World Health Organization. Soc Psychiatry Psychiatric Epidemiol. 1996;31 (2): 55-69. Review.

12. Chaves AC, Pinto RN, Lourenço MT, Mari JJ. Chance of psychiatric morbidity amongst recently diagnosed cancer outpatients attending a chemotherapy unit. Braz J Med Biol Res. 2005;38(9):1423-7.

13. Arce-Salinas C, Aguilar-Ponce JL, Villarreal-Garza C, Lara-Medina FU, Olvera-Caraza D, Alvarado Miranda A, et al. Overweight and obesity as poor prognostic factors in locally advanced breast cancer patients. Breast Cancer Res Treat. 2014;146(1):183-8.

14. Keskin O, Aksoy S, Babacan T, Sarici F, Kertmen N, Solak M, et al. Impact of the obesity on lymph node status in operable breast cancer patients. $J$ BUON. 2013;18(4):824-30.

15. Seshadri R, Matthews C, Dobrovic A, Horsfall DJ. The significance of oncogene amplification in primary breast cancer. Int J Cancer. 1989;43(2):270-2. Review.

16. Engstrøm MJ, Opdahl S, Hagen Al, Romundstad PR, Akslen LA, Haugen OA, et al. Molecular subtypes, histopathological grade and survival in a historic cohort of breast cancer patients. Breast Cancer Res Treat. 2013;140(3):463-73.

17. Yarden Y. Biology of HER2 and its importance in breast cancer. Oncology 2001;61 Suppl 2:1-13. Review.

18. Lucarelli $A P$, Martins $M M$, Montor W, Oliveira V, Galvão MA, Piato $S$, Cyclooxygenase-2 and human epidermal growth factor receptor type 2 (HER-2) expression simultaneously in invasive and in situ breast ductal carcinoma. Sao Paulo Med J. 2011;129(6):371-9.

19. Vazquez-Martin A, Colomer, R, Brunet J, Lupu R, Menendez JA. Overexpression of fatty acid synthase gene activates HER1/HER2 tyrosine kinase receptors in human breast epithelial cells. Cell Prolif. 2008;41(1):59-85.

20. Menendez JA. Fine-tuning the lipogenic/lipolytic balance to optimize the metabolic requirements of cancer cell growth: molecular mechanisms and therapeutic perspectives. Biochim Biophy Acta. 2010;1801(3):381-91. Review.

21. Amer MH. Genetic factors and breast cancer laterality. Cancer Manag Res. 2014:6:191-203. 